


\section{Antonio Candido pioneiro}

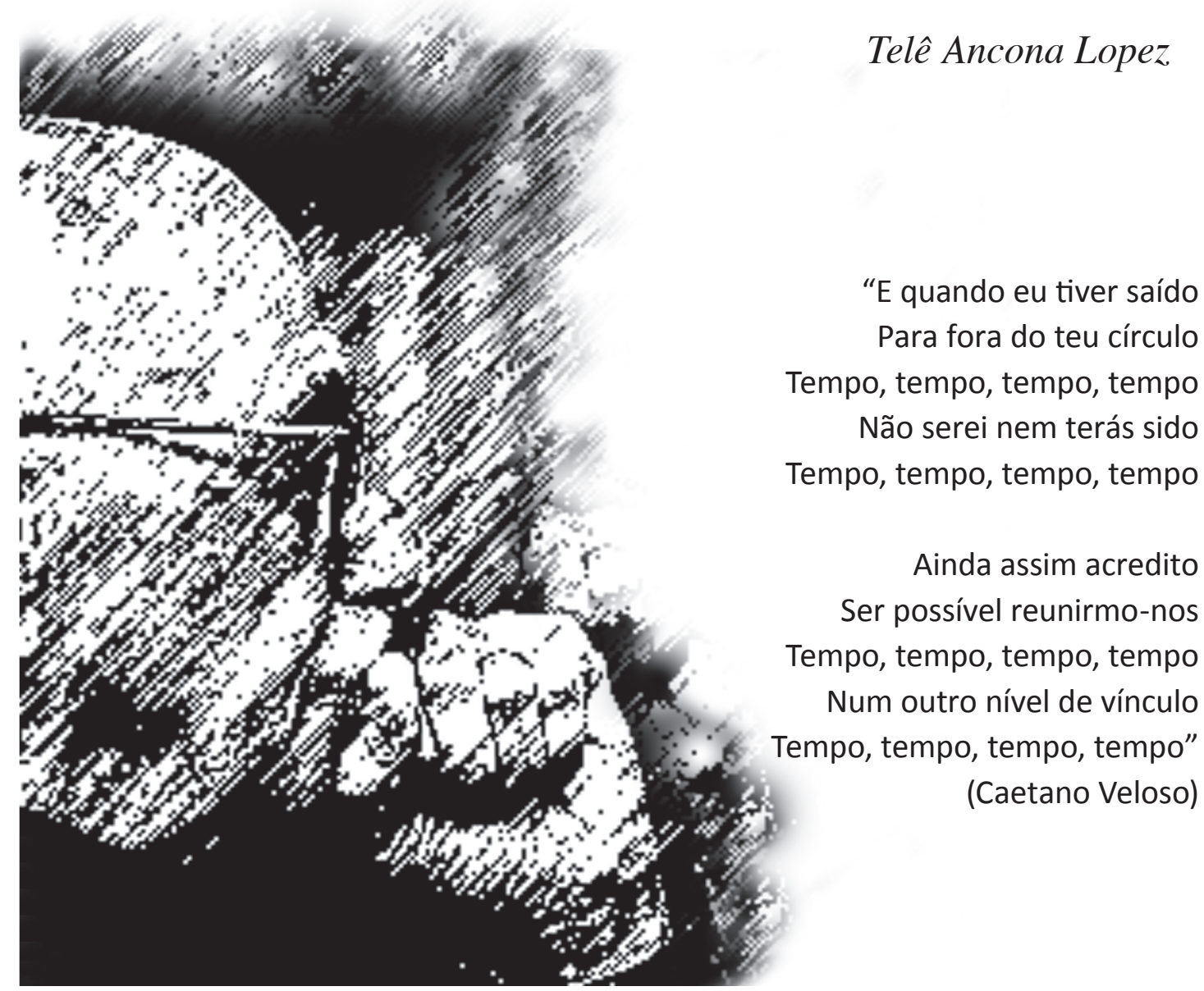

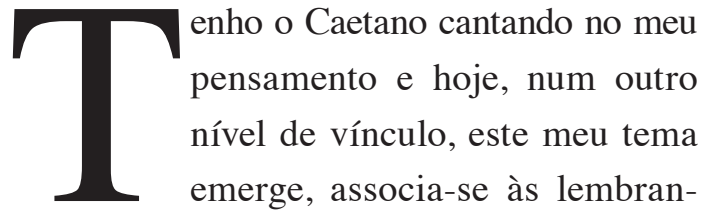

ças, costurando-as na medida do depoimento, tempo de historiar para esta aluna de Antonio Candido que eu sou, por toda a minha vida.

Recém-formada, descubro Antonio Candido de Mello e Souza pioneiro, no segundo semestre de 1961, quando ele abre para a interdisciplinaridade as fronteiras do ensino da literatura. Seu curso Teoria e Análise do Romance, na área nova, Teoria Literária e Literatura Comparada, da Faculdade de Filosofia, Ciências e Letras (hoje Faculdade de Filosofia, Letras e Ciências Huma- nas) da Universidade de São Paulo, enseja o seminário interdisciplinar "A Personagem de Ficção", que ele coordena após as aulas, de outubro a novembro, no prédio cinza de altivas colunas, à Rua Maria Antonia. Com-

Meu agradecimento aos amigos que, generosamente, compartilharam comigo informações por eles recolhidas em projetos seus: professores Antonio Dimas e Thiago Lima Nicodemo, que estudam, respectivamente, a interlocução IEB-USP/Fapesp e Sérgio Buarque de Holanda na formação do IEB-USP.

TELÊ ANCONA LOPEZ é Professora Emérita do IEB-USP e colaboradora-sênior do IEB e da FFLCH-USP. 
pareço ao seminário. Conferencistas convidados, excelentes, ocupam-se de focos paralelos ao da teoria e da análise literária: Anatol Rosenfeld aborda a questão geral da ficção; Decio de Almeida Prado, a personagem de teatro; Paulo Emílio Sales Gomes, a personagem de cinema; Antonio Candido cuida da personagem na literatura. Há mesa-redonda com a participação de alunos, projeção de filme, peça teatral, debates. Tudo coisa nova, facultada à comunidade, como se diz atualmente. Em 1964, o número 284 do Boletim da Faculdade de Filosofia, Ciências e Letras, intitulado A Personagem de Ficção, divulga os ensaios dos quatro conferencistas no seminário de 1961. O prefácio de Antonio Candido à segunda edição, pela Editora Perspectiva, em 1968, destaca a primeira publicação como um livro "nascido de uma experiência de ensino".

O renovar, inerente aos passos de Antonio Candido, reitera 1962, na chave da interdisciplinaridade, no primeiro semestre, durante o curso de especialização em que se estuda Quincas Borba, das 10 horas ao meio-dia, às sextas-feiras, na sala 11 , a sala grande no primeiro andar. Sou aluna matriculada. $\mathrm{Na}$ análise minuciosa e na interpretação do texto, regidas pelo professor, a crítica literária traça pontes com a sociologia, o cinema e a pintura. As aulas garantem voz aos alunos inscritos e àqueles que se achegam, atraídos pelo valor da discussão. Os alunos "de fora" são estudantes de outras áreas e pessoas que levantam questões interessantes - a escritora Lygia Fagundes Telles, Paulo Emílio Sales Gomes, Maurice Capovilla, cineasta e ator, jornalistas, um rato de biblioteca, duas senhoras da haute gomme paulistana, d. Ivonne, d. Nelia, cultas e gentis. Dessa disciplina sai o projeto de Antonio Candido para a sua aluna Pérola de Carvalho - reunir o jornalismo do Machado, transcrevendo crônicas e críticas diretamente dos jornais e revistas conservados na Biblioteca Nacional, no Rio de Janeiro. O projeto põe em cena o ensino da pesquisa literária nas fontes primárias. Para concretizá-lo, o orientador, em 1963, apresenta à Fapesp, então compromissada com a investigação nas ciências exatas e biológicas, o pedido de bolsa para o projeto de Pérola, no âmbito de um doutoramento. Concedida a bolsa, o desempenho da pesquisadora é exemplar, dizem os pareceres aos relatórios da nossa colega.

Cronista, eu regresso a 1962, ao segundo semestre e ao curso de especialização, desta vez mergulhada na análise e na interpretação do poema de Mário de Andrade, "Louvação da Tarde", no Modernismo que ainda arreliava muita gente. $\mathrm{O}$ estudo meticuloso, que Antonio Candido desenvolve, motiva dois caminhos, de 1963 a 1968, unindo estreitamente o grande polígrafo à Universidade de São Paulo.

O caminho imediato é inaugurar, na universidade brasileira, o estudo das bibliotecas de escritores, concretizado na pesquisa que visa ao levantamento dos títulos e à coleta da marginália nas estantes de Mário de Andrade. Desponta em uma das nossas aulas (talvez ideia matreiramente lançada...). Nosso professor nos conta - e bem me lembro do sorriso nos olhos dele - que a imensa biblioteca do poeta de Pauliceia Desvairada possui uma igualmente imensa marginália e que tudo está lá, intocado, na casa onde ele viveu, à Rua Lopes Chaves, 546, na Barra Funda. Entusiasmada, mas delirando, eu proponho que, nas férias, nós, seus alunos de teoria literária, registremos tudo. A verdade é que demorou um pouco... Em janeiro de 
1963, Maria Helena Grembecki e eu começamos a trabalhar, guiadas pelo nosso mestre, no tombamento dos títulos e na transcrição das notas marginais. O projeto, em 1965, admite mais uma pesquisadora, Nites Feres. E nós só conseguimos fechá-lo em 1968, isso porque recorremos à microfilmagem com uma Leica, acoplada a um incrível aparelho inventado pelo professor José Aderaldo Castello, então diretor do Instituto de Estudos Brasileiros, personagem e entidade significativos neste meu relembrar, como logo se verá. Àquela altura, já contamos com o respaldo financeiro da Fapesp. Ao solicitar bolsas para nós duas, em janeiro de 1964, Antonio Candido ressaltara a relevância da biblioteca de Mário de Andrade, "superior a 10.000 volumes”, nas multíplices áreas que a compõem, enriquecidos com as copiosas anotações daquele especial leitor. Para convencer a Fapesp da necessidade de captar os títulos e recolher a marginália, o professor se referira à marginália de Stendhal, coligida e publicada pela Universidade de Grenoble. Frisara o ineditismo do seu próprio empreendimento:

"No quadro das tentativas (em que estamos empenhados) de trazer a pesquisa humanística, no Brasil, ao nível já alcançado nas ciências físicas e biológicas, estou certo de que o projeto agora apresentado merece consideração, pela matéria investigada e pela qualidade das duas investigadoras".

Pouco depois, ele vincularia nossa pesquisa ao mestrado implantado pela área de Teoria Literária e Literatura Comparada na faculdade. E orientaria as dissertações de mestrado de suas três pesquisadoras, defendidas em 1967. Sobre a marginália de Mário de Andrade, naturalmente! Em 1968, ao findar o registro da biblioteca e da marginália, as fichas e os microfilmes resultantes da nossa pesquisa são depositados no instituto e franqueados à consulta.

O segundo caminho nascido do curso de especialização consolida a democratização do saber na esfera das humanidades, ao contemplar a salvaguarda do acervo do criador de Macunaíma e o acesso ao seu conteúdo. E me faz voltar a uma tarde de agosto, em 1967. Tanto quanto pode meu olhar se deter em Antonio Candido, ele chega - paletó de tweed e boina - à casa da Lopes Chaves, para supervisionar nosso trabalho. Conta-nos do Instituto de Estudos Brasileiros, criado dentro da USP pelo historiador Sérgio Buarque de Holanda, em 1962, um órgão composto de várias áreas integradas, no qual, como conselheiro ligado à literatura, ele defende a pesquisa nas fontes primárias e a internacionalização de projetos. Pois esse IEB - como se fala então, escandindo a sigla - tem agora, na direção, José Aderaldo Castello, um professor de literatura brasileira que, compreendendo o alcance do Acervo Mário de Andrade, deseja firmemente incorporá-lo ao patrimônio da instituição. Antonio Candido sonha um centro de estudos do Modernismo; aplica-se, de corpo e alma, à negociação com o governo do Estado no intuito de obter a aquisição do acervo para a Universidade de São Paulo, já determinado ao IEB. Castello luta ao seu lado. A transação se consuma em 1968. A família de Mário, que, desde a morte dele, em 1945, zelara do arquivo, dos livros, das obras de arte plásticas, da imaginária religiosa e dos objetos da cultura popular, no espólio de valor incalculável, que generosamente recebera as pesquisadoras em sua casa, revela 
plena compreensão do destino do acervo, quando aceita o pagamento simbólico do Estado, envolvendo a biblioteca e a coleção de arte. Doa o arquivo ao IEB. De lá para cá, perde-se a conta dos projetos universitários, nas áreas de artes plásticas, música, fotografia, filosofia, sociologia, antropologia, teoria literária e literatura comparada, literatura brasileira, bem como nas literaturas de outras nacionalidades que, na USP e fora dela, se abeberaram do acervo, votando-se ou não à obra do multi-Mário. Testemunha-se, igualmente, o sem-número de pesquisadores que, sem objetivos acadêmicos, ali apoiam as respectivas investigações.

Eu me atraso em conhecer o que, para mim, representa mais uma instância pioneira no trajeto de Antonio Candido professor. Prende-se a 1959 e à crítica textual, creio que nunca antes especificamente ensinada na universidade brasileira. Em 1977, como pesquisadora concursada do IEB, devo preparar uma edição crítica de Macunaíma para a coleção Biblioteca Universitária de Literatura
Brasileira, dirigida pelo professor Castello. Peço socorro ao meu mestre, com quem, há algum tempo, eu avalio critérios para editar inéditos do Mário de Andrade. Desta vez, suas respostas pontuais são acompanhadas de um presentão - a apostila Noções de Análise Histórico-Literária, mimeografada (datilografia dele) para a disciplina homônima que ele lecionara, em 1959, na Faculdade de Ciências e Letras de Assis, fundamentando-se em Pasquali, Jannaco, Paul Maas, livros que passam, igualmente, para minhas mãos. Em 2005, "depois de muita relutância", Antonio Candido consente em divulgar, pela Associação Editorial Humanitas, essas suas aulas, surpreendendo muita gente.

Esses três instantes, sobre os quais me inclino, eu os vejo no bojo de um pensamento, de uma vida que compreendeu o direito inalienável da humanidade de exercer e de fruir a literatura e todas as artes, em um sentido de liberdade e justiça, fundamental para a evolução emocional e ética dessa mesma humanidade - Antonio Candido. 